\title{
Effects of Planting Density and Methods of Raising Seedlings on Flowering, Yield and Quality of Cut Flowers in Snapdragons (Antirrhinum majus L.)
}

\author{
Zentaro INABA and Miyuki OHSHIRO \\ Shizuoka Agricultural Experiment Station Minamiizu Branch, \\ Minamiizu-cho, Shizuoka 415-0302, Japan
}

(Received April 28, 2005)

\begin{abstract}
Effects of planting density and raising seedling method on the flowering, yield and quality of snapdragon (Antirrhinum majus L.) were investigated. Plants were sown in July and pinched in September. In experiment 1, 'Maryland Pink' and 'Light Pink Butterfly II' were pinched at the temporary planting stage followed by planting at a density of 4,6 or 8 plants per row. The yield of cut flowers per plant decreased with an increase in planting density. However, the yield of cut flowers per square meter was significantly less in 4 plants per row than in 6 and 8 plants per row. The number of days from pinching to flowering and cut flower quality were not affected by the planting density. In experiment 2, 'Maryland Pink' was non-temporary planted with the same density as in experiment 1 or planted after temporary planting as a conventional method with 6 plants per row. Effect of planting density in non-temporary planting was similar to that of 'Maryland Pink' in experiment 1. The flowering of the primary shoots on the second node was earlier in non-temporary planting than in the conventional method, and the yield of cut flowers was greater in the former than in the latter. The results show that the productivity was higher in raising seedlings without temporary planting than in the conventional method.
\end{abstract}

Keywords: pinching cultivation, planting density, seedling method, snapdragon, temporary planting

\section{INTRODUCTION}

Pinching cultivation is general for snapdragon (Antirrhinum majus L.) production in warm districts in Japan (Inaba, 1994). However, non-pinching cultivation is carried out in the USA Snapdragons have been classified into four groups based on temperature and photoperiodic response and other characters. Four groups whose earliness differs have been selected for seasonallyclassified flowering time. Group I cultivars require the shortest period for flowering, followed by Group II cultivars (Rogers, 1992; Corr and Laughner, 1998).

Group I and II cultivars have been selected for pinching cultivation in Japan. Flowers are harvested from autumn to spring for about 5 to 7 months (Inaba, 2001). In production regions, the promotion of secondary flowering and increase in the yield of cut flowers have been required (Inaba, 1994). We studied the regulation of flowering and yield of cut flowers by night temperature (Inaba and Ohtsuka, 2002; Inaba and Oshiro, 2004), long day (Inaba and Horiuchi, 2003) and

Corresponding author: Zentaro Inaba, fax : +81-558-62-0129, e-mail : z-inaba@agri-exp.pref.shizuoka.jp 
pinching methods (Inaba et al., 1997). Based on the results, we have clarified the growth characteristics of snapdragons in the pinching cultivation.

In the production of carnation cut flowers, which are harvested from autumn to spring, like snapdragons, in warm districts in Japan, there have been many studies on the planting density. The yield of cut flowers per area increased and those per plant decreased with increasing planting density in carnation, and there have been various planting modes according to the characteristics of cultivars (Yonemura, 1990). However, there are few reports on planting density of snapdragons. Inaba (1994) described that the yield of cut flowers per plant decreased with increasing planting density using cultivars which had been produced in conventional production. Most cultivars at present in Japan are $F_{1}$ hybrids introduced from foreign countries since 1985. These cultivars are suitable for non-pinching cultivation (Rogers, 1992; Corr and Laughner, 1998). In the production region, heating was carried out to prevent freezing when these cultivars were introduced. The heating temperature has been $11^{\circ} \mathrm{C}$ at night by a standard based on our research (Inaba, 2001). However, there has been no study on the planting density suitable for cultivar characteristics and cultivation condition.

In the production region including Shizuoka prefecture, seedlings were planted shortly after the cotyledons developed, pinched and finally planted steadily (conventional method) (Inaba, 1994; Hosoya, 1994; Keida, 1994). In recent years, some production regions have adopted seedlings raised without temporary planting (non-temporary planting) in a container using marketed soil (Abe and Sasaki, 1994; Inaba, 2001). Raising seedlings without temporary planting seems to save more labor than the conventional method. In our research, the flowering of the primary shoots from the second node was accelerated and the yield of cut flowers was increased by non-temporary planting more than those by the conventional method (Inaba and Ohshiro, 2004). Furthermore, there were differences in the growth characteristics after planting between the two methods for raising seedlings (Inaba and Ohshiro, 2004). Thus, an examination of the relationship between nursing seedling method and planting density is required.

The purpose of this study is to develop a cropping type in the pinching cultivation of snapdragons in warm places in Japan. In experiment 1, the effect of the planting density on flowering, yield and quality of cut flowers in 'Maryland Pink', a Group I cultivar (Corr and Laughner, 1998) and 'Light Pink Butterfly II', a Group II cultivar (Inaba and Ohtsuka, 2002) was examined with the seedlings raised by the conventional method. In experiment 2 , the effects of the planting density and methods of the raising seedlings in 'Maryland Pink' were examined.

\section{MATERIALS AND METHODS}

\section{Plant materials and cultivation conditions}

Experiments were carried out using soil beds $80 \mathrm{~cm}$ wide, north and south-facing in a glasscovered greenhouse $\left(148 \mathrm{~m}^{2}\right)$ in Shizuoka Agricultural Exp. Stn. Minamiizu branch. The distance between rows was $20 \mathrm{~cm}$. The alleyways between soil beds ran east-west, and they were $60 \mathrm{~cm}$ wide. Figure 1 shows three different planting densities in $0.48 \mathrm{~m}^{2}$ with 3 rows; (a) 8, (b) 6 and (c) 4 plants per row. Closed circle $(-$ ) shows individual plants. Planting numbers per square meter were $50,37.5$ and 25 plants for 8,6 , and 4 plants per row, respectively. The total numbers of plants at 8,6 and 4 plants per row were 24, 18 and 12 plants, respectively. Experiments 1 and 2 were repeated twice. Planting density was determined on the basis of Yonemura (1990).

About three hundred seeds were sown in a L size container (length $33 \mathrm{~cm}$, width $47 \mathrm{~cm}$, depth $7 \mathrm{~cm}$ ) which was filled with marketed medium (Yosaku N-150, Chisso-Asahi Fertilizer Co., Ltd., Japan). Seedlings were planted shortly after the cotyledons developed. The temporary planted floor was filled with disinfected soil which was mixed with mountain soil and bark compost in a ratio of 2:1, and supplied with coated fertilizer (Long 424180 day-type, Chisso-Asahi Fertilizer 


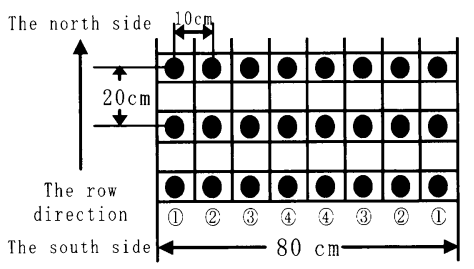

a

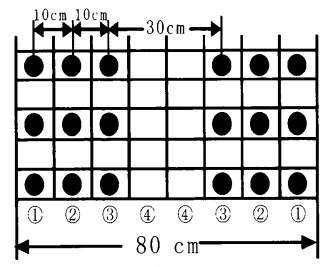

b

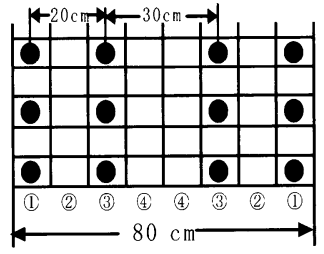

C

Fig. 1 Diagrams showing three different planting densities in $0.48 \mathrm{~m}^{2}$ with 3 rows $0.8 \mathrm{~m}$ long and $0.2 \mathrm{~m}$ apart. 8 plants/row (a), 6 plants/row (b), 4 plants/row (c). Closed circle (O) shows each plant.

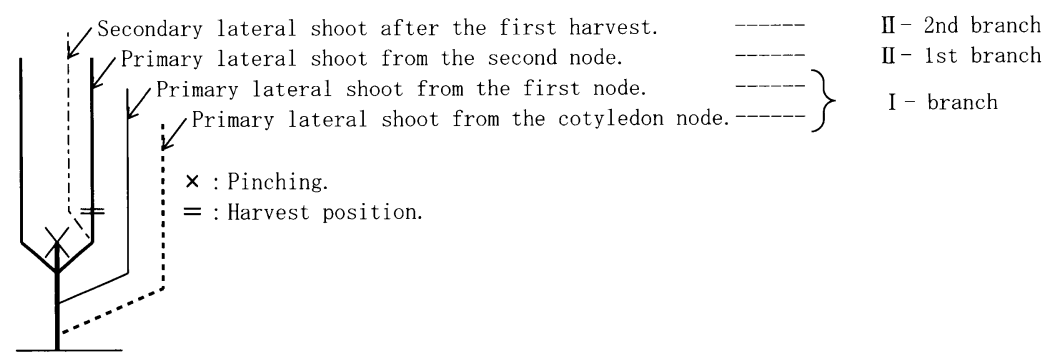

Fig. 2 Diagram showing shoots generated from different nodal positions.

Co., Ltd., Japan) at $20 \mathrm{~g}$ per $\mathrm{m}^{2}$. To raise seedlings by non-temporary planting, seedlings were grown in a container until they were planted. Fertilizers were applied to the soil bed before planting and after the start of harvesting. The amounts of $\mathrm{N}, \mathrm{P}_{2} \mathrm{O}_{5}$ and $\mathrm{K}_{2} \mathrm{O}$ were $1.4,1.6$ and $1.8 \mathrm{~kg} \mathrm{a}^{-1}$, respectively. Plants were pinched above the second node. The generated primary and secondary lateral shoots after pinching were not arranged. The flowering date was determined as the time when 4 florets in a spike opened. All flowered shoots were harvested above a lowest node from the branch position. Days from pinching to flowering, cut flower length, nodal number generated from different positions were measured. According to a standard in the producing area, cut flowers were judged as to whether they had a marketable value. The number of cut flowers generated from different nodal positions in respective rows, which are shown in Fig. 1, was scored.

Figure 2 shows the shoots generated from different nodal positions. In both cultivars flowered in the following order: first in primary shoots formed from the second node after pinching (II1 st branch), then in shoots from the first node and the cotyledonary node in which flowers bloomed almost simultaneously (I-branch), and finally in secondary shoots from lateral shoots from the second node (II-2nd branch).

Experiment 1: Effect of planting density on yield and quality of cut flowers in snapdragons raised by the conventional method

'Maryland Pink' and 'Light Pink Butterfly II' were sown on July 30, 2000, temporary planted on August 16, pinched on September 8 and planted on September 16. The night temperature was set at $11^{\circ} \mathrm{C}$ after November 25 . The yield and quality of cut flowers were examined from the start of flowering to March 31, 2001.

Experiment 2: Effect of planting density on yield and quality of cut flowers in 'Maryland Pink' raised by non-temporary planting

For non-temporary planting, 'Maryland Pink' was sown on July 31, 2001, planted on August 30 and pinched on September 10. In the conventional method (with temporary planting), 'Maryland Pink' was sown on July 31, 2001, temporary planted on August 15, pinched on September 10 and planted on September 17. Planting density at 6 plants per row was only examined for the 
Table 1 Effects of planting density on the number of days from pinching to flowering ${ }^{z}$ at each shoot generated from different nodal positions of snapdragon. Plants were sown on July 30, 2000, temporarily planted on August 16, pinched on September 8, planted on September 16 (Same as Tables 2 and 3).

\begin{tabular}{|c|c|c|c|c|c|c|}
\hline \multirow{2}{*}{$\begin{array}{l}\text { Planting } \\
\text { density }\end{array}$} & \multicolumn{3}{|c|}{ 'Maryland Pink' } & \multicolumn{3}{|c|}{ 'Light Pink Butterfly II' } \\
\hline & $\begin{array}{l}\text { II-1st branch } \\
\text { (days) }\end{array}$ & $\begin{array}{l}\text { I-branch } \\
\text { (days) }\end{array}$ & $\begin{array}{l}\text { II-2nd branch } \\
\text { (days) }\end{array}$ & $\begin{array}{l}\text { II-1st branch } \\
\text { (days) }\end{array}$ & $\begin{array}{c}\text { I-branch } \\
\text { (days) }\end{array}$ & $\begin{array}{l}\text { II-2nd branch } \\
\text { (days) }\end{array}$ \\
\hline 4 plants/row & 75 & 189 & 194 & 69 & 192 & 197 \\
\hline 6 plants/row & 77 & 186 & 192 & 68 & 180 & 196 \\
\hline 8 plants/row & 81 & 190 & 193 & 69 & 189 & 195 \\
\hline Significance $^{x}$ & NS & NS & NS & NS & NS & NS \\
\hline
\end{tabular}

'Flowering date was determined when four florets had bloomed (Same as Table 4).

'Nodal position (II-1st branch, I-branch and II-2nd branch) was shown in Fig. 2 (Same as Tables 2, 3, 4, 5 and $6)$.

'NS: Non significant.

conventional method. The night temperature was set at $11^{\circ} \mathrm{C}$ from November 25 . The yield and quality of cut flowers were examined from the start of harvest to March 31, 2002.

\section{RESULTS}

Experiment 1: Effect of planting density on yield and quality of cut flowers in snapdragons raised by the conventional method

In both cultivars, the number of days from pinching to flowering was not affected by planting density (Table 1). The yield of cut flowers per plant decreased with increasing planting density. Yield of cut flowers at 4 and 6 plants per row were almost the same, but significantly less than those at 8 plants per row in both cultivars. The decrease in yield of cut flowers in 'Maryland Pink' and 'Light Pink Butterfly II' was due to a decrease in II-2nd branch and I-branch, respectively. The yield of cut flowers per square meter at 6 and 8 plants per row was significantly higher than that at 4 plants per row in both cultivars (Table 2).

Relatively high yields per plant were obtained on the alley side of rows regardless of planting density, and yield decreased with when proximating the center of the row. This decrease was remarkable at 8 plants per row (Fig. 3).

The planting density did not influence the cut flower length and nodal number (Table 3 ). The number of cut flowers which have potential marketable value increased at 6 and 8 plants per row (data not shown).
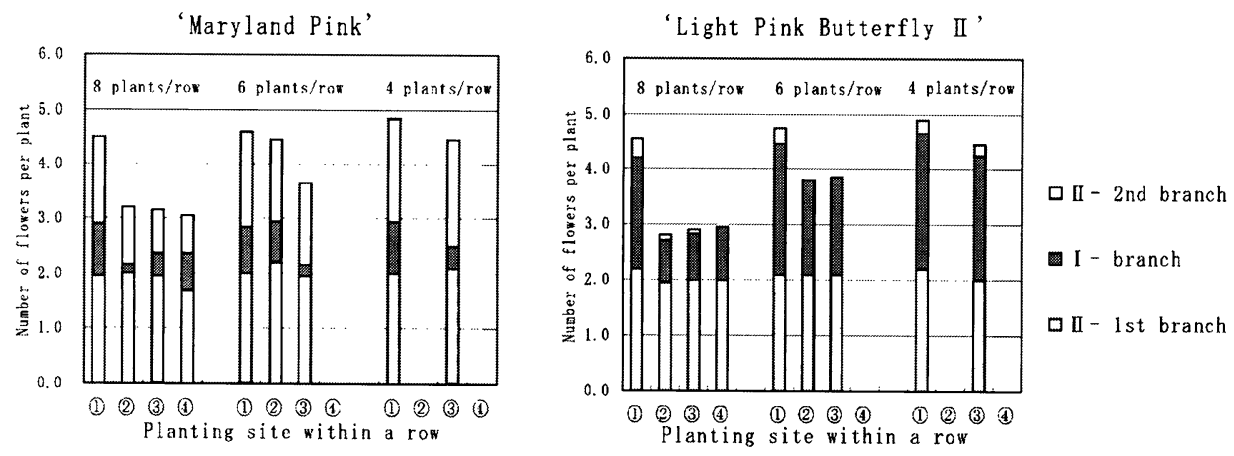

Fig. 3 Effects of planting site whithin a row on the number of cut flowers generated from different nodal positions of snapdragon. Planting sites within a row are shown in Fig. 1. 


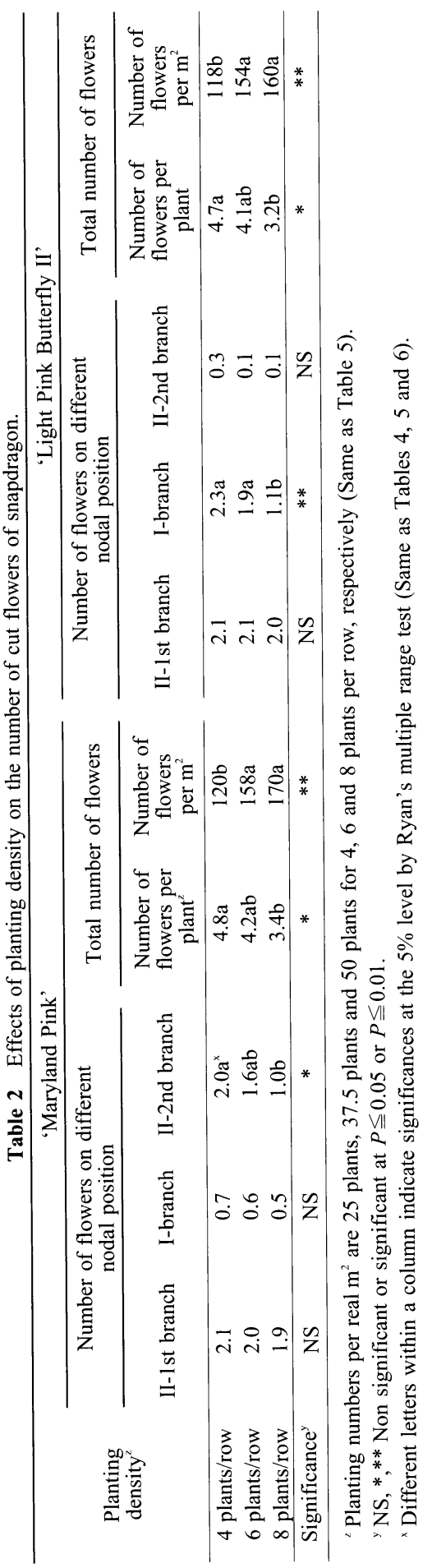


Table 3 Effects of planting density on the length of cut flower stems generated from different nodal positions of snapdragon.

\begin{tabular}{ccccccccc}
\hline \multirow{2}{*}{$\begin{array}{c}\text { Planting } \\
\text { density }\end{array}$} & $\begin{array}{c}\text { II-1 st branch } \\
(\mathrm{cm})\end{array}$ & $\begin{array}{c}\text { I-branch } \\
(\mathrm{cm})\end{array}$ & \begin{tabular}{c} 
II-2nd branch \\
\cline { 8 - 9 } \cline { 7 - 8 }
\end{tabular} & & $\begin{array}{c}\text { II-1st branch } \\
(\mathrm{cm})\end{array}$ & & $\begin{array}{c}\text { I-branch } \\
(\mathrm{cm})\end{array}$ & $\begin{array}{c}\text { II-2nd branch } \\
(\mathrm{cm})\end{array}$ \\
\hline 4 plants/row & 106 & 109 & 99 & & 65 & 84 & 86 \\
6 plants/row & 102 & 113 & 94 & & 65 & 106 & 89 \\
8 plants/row & 101 & 109 & 96 & & 64 & 104 & 81 \\
\hline Significance & NS & NS & & NS & & NS & NS & NS \\
\hline
\end{tabular}

${ }^{`}$ NS: Non significant.

Experiment 2: Effect of the planting density on yield and quality of cut flowers in 'Maryland Pink' raised by non-temporary planting

The planting density did not affect the number of days from pinching to flowering when seedlings were raised by non-temporary planting. In the conventional method of raising seedling, days from pinching to flowering of II-1st branches were 90 days, increasing by 30 days as compared to non-temporary planting (Table 4).

The yield of cut flowers per plant decreased with increasing planting density. The yield of cut flowers per square meter at 4 plants per row was significantly less than that at 6 and 8 plants per row. However, there was no significant difference in the yield of cut flowers per square meter between 6 and 8 plants per row. The yield of cut flowers per square meter at 6 plants per row in the conventional method was significantly less than that in non-temporary planting, and it was similar to that of 4 plants per row in non-temporary planting (Table 5).

Table 4 Effects of planting method and density on the number of days from the pinching to flowering at each shoot generated from different nodal positions of snapdragon 'Maryland Pink'.

\begin{tabular}{|c|c|c|c|c|}
\hline Planting method & Planting density & $\begin{array}{l}\text { II-1 st branch } \\
\text { (days) }\end{array}$ & $\begin{array}{c}\text { I-branch } \\
\text { (days) }\end{array}$ & $\begin{array}{l}\text { II-2nd branch } \\
\text { (days) }\end{array}$ \\
\hline With temporary planting ${ }^{2}$ & 6 plants/row & $90 \mathrm{a}$ & 159 & 191 \\
\hline \multirow[t]{3}{*}{ Direct planting } & 4 plants/row & $62 \mathrm{~b}$ & 159 & 182 \\
\hline & 6 plants/row & $61 b$ & 168 & 182 \\
\hline & 8 plants/row & $60 \mathrm{~b}$ & 159 & 191 \\
\hline \multicolumn{2}{|c|}{ Significance $^{r}$} & $* *$ & NS & NS \\
\hline
\end{tabular}

${ }^{2}$ Plants were sown on July 31, 2001. temporary planted on August 15. pinching on September 10. planted on September 17.

${ }^{y}$ Plants were sown on July 31, 2001. planted on August 30. pinched on September 10 and planted on September 17 (Same as Tables 5 and 6).

${ }^{*} \mathrm{NS},{ }^{* *}$ Non significant or significant at $P \leqq 0.01$.

Table 5 Effects of planting method and density on number of cut flowers of snapdragon 'Maryland Pink'.

\begin{tabular}{|c|c|c|c|c|c|c|}
\hline \multirow{2}{*}{ Planting method } & \multirow{2}{*}{$\begin{array}{l}\text { Planting } \\
\text { density }\end{array}$} & \multicolumn{3}{|c|}{$\begin{array}{l}\text { Number of flowers on different } \\
\text { nodal position }\end{array}$} & \multicolumn{2}{|c|}{ Total number of flowers } \\
\hline & & $\begin{array}{l}\text { II-1st } \\
\text { branch }\end{array}$ & I-branch & $\begin{array}{l}\text { II-2nd } \\
\text { branch }\end{array}$ & $\begin{array}{l}\text { Number of } \\
\text { flowers } \\
\text { per plant }\end{array}$ & $\begin{array}{c}\text { Number of } \\
\text { flowers } \\
\text { per } \mathrm{m}^{2}\end{array}$ \\
\hline With temporary planting & 6 plants/row & 1.8 & 1.2 & $0.8 \mathrm{bc}$ & $3.8 \mathrm{bc}$ & $143 \mathrm{~b}$ \\
\hline \multirow[t]{4}{*}{ Direct planting } & 4 plants/row & 2.0 & 2.0 & $1.3 \mathrm{a}$ & $5.3 \mathrm{a}$ & $133 b$ \\
\hline & 6 plants/row & 2.0 & 1.8 & $1.2 \mathrm{ab}$ & $5.0 \mathrm{ab}$ & $188 \mathrm{a}$ \\
\hline & 8 plants/row & 2.0 & 1.4 & $0.7 \mathrm{c}$ & $4.1 \mathrm{c}$ & $205 \mathrm{a}$ \\
\hline & Significance $^{2}$ & NS & NS & $*$ & $*$ & $*$ \\
\hline
\end{tabular}

${ }^{2} \mathrm{NS},{ }^{*}$ Non significant or significant at $P \leqq 0.05$. 


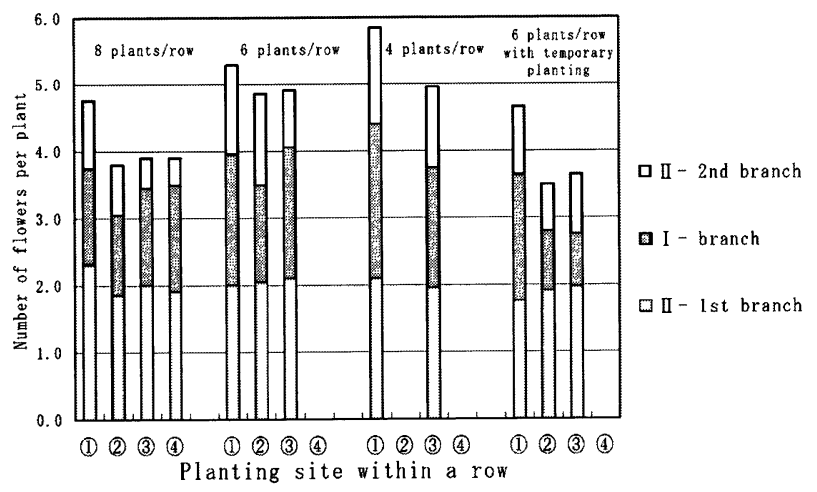

Fig. 4 Effects of planting site within a row on the number of cut flowers generated from different nodal positions of snapdragon 'Maryland Pink'. Planting sites within a row are shown in Fig. 1.

Table 6 Effects of planting method and density on the length of cut flower stems generated from different nodal positions of snapdragon 'Maryland Pink'.

\begin{tabular}{lcccc}
\hline Planting method & Planting density & $\begin{array}{c}\text { II-1st branch } \\
(\mathrm{cm})\end{array}$ & $\begin{array}{c}\text { I-branch } \\
(\mathrm{cm})\end{array}$ & $\begin{array}{c}\text { II-2nd branch } \\
(\mathrm{cm})\end{array}$ \\
\hline With temporary planting & 6 plants/row & $90 \mathrm{a}$ & 159 & 191 \\
Direct planting & 4 plants/row & $62 \mathrm{~b}$ & 159 & 182 \\
& 6 plants/row & $61 \mathrm{~b}$ & 168 & 182 \\
& 8 plants/row & $60 \mathrm{~b}$ & 159 & 191 \\
\hline & & $* *$ & NS & NS \\
\hline
\end{tabular}

${ }^{2} \mathrm{NS},{ }^{* *}$ Non significant or significant at $P \leqq 0.01$.

The yield of cut flowers per plant was greatest on the alley side of rows regardless of planting density, and the number of cut flowers per plant decreased when proximating the center of the row (Fig. 4).

The planting density did not influence the length of cut flowers. However, the length of cut flowers from II-1 st branches in the conventional method were $90 \mathrm{~cm}$ and significantly longer than those in the other treatment (Table 6). The planting density did not affect the nodal number. The number of cut flowers which have potential marketable value increased to 6 to 8 plants per row in non-temporary planting (data not shown).

\section{DISCUSSION}

In the present study, there was no difference in the number of days from pinching to flowering in the branches generated from respective positions among different planting densities when methods for raising seedlings were the same. Inaba et al. (1997) clearly showed that the harvesting time of flowers from II-1st branches could be controlled by the time of pinching, but those from Ibranches and II-2nd branches could not be controlled by the pinching time in the conventional (seedling) method, although the flowering of snapdragons was accelerated by high night temperatures (Sanderson and Link, 1967; Inaba and Ohtsuka, 2002; Inaba and Horiuchi, 2003; Inaba and Ohshiro, 2003) and longday (Flint, 1960; Maginnes and Langhans, 1961; Sanderson and Link, 1967; Hedley, 1974; Inaba and Horiuchi, 2003). Experiment 1 and 2 were carried out in the same greenhouse. These results indicate that the planting density does not affect the flowering time when cultivation conditions, except for planting density, are the same.

There are a few reports on the planting density of snapdragons. Inaba (1994) reported with 


\section{Z. INABA AND M. OHSHIRO}

old cultivars in production regions that the yield of cut flowers per plant decreased with increasing planting density. Similar results were obtained in 'Maryland Pink' and 'Light Pink Butterfly II', which are the main cultivars in production regions since 1985 (Inaba, 2001).

These two cultivars were bred in the USA for non pinching cultivation (Rogers, 1992; Corr and Laughner, 1998). There were differences in the yield of cut flowers generated from different positions between these cultivars in pinching cultivation: The yields of cut flowers from I-branches in 'Light Pink Butterfly II' and those from II-2nd branches in 'Maryland Pink' increased at 4 and 6 plants per row, respectively although planting density did not affect the flowering time of II-1st branches.

Yonemura (1990) suggested that the planting density could be changed according to the earliness of the cultivars in carnation. There was a difference in earliness between 'Maryland Pink' and 'Light Pink Butterfly II' (Inaba and Ohshiro, 2003). In the pinching cultivation of snapdragons, ensuring the yield of cut flowers in the winter season is required (Inaba, 1994). Thus, a density of 6 plants per row seems to be suitable because the large yields of I-branches and II-2nd branches per square meter were obtained in both cultivars.

The yield of cut flowers per plant was the largest on the alley side of rows, and it decreased when the side was closed. The yield of cut flowers in the central row decreased more with increasing planting density. Inaba (1994) reported that the number of branches per plant was affected by planting density. A similar result was reported by Yonemura (1990) for carnation. According to studies on pinching methods and flowering characteristics of snapdragons, the number of branches was found to increase when plants were pinched twice (Inaba et al., 1997). Increase in branch number reduces light intensity for photosynthesis. To keep the light intensity for photosynthesis, the planting density at 4 plants per row was recommended (Inaba et al., 1997). In pinching cultivation of 'Light Pink Butterfly II', yields of cut flowers in winter was found to be increased by long day treatment from the end of November (Inaba and Horiuchi, 2003). These findings suggest that the light environment inside the row is changed by the increase in planting density, which may reduce the yields of I-branches and II-2nd branches in the row except for the alley way side. In carnation whose planting density is often similar to that of snapdragons, suitable planting density was found to be $37.5^{-50}$ plants per square meter (Tanaka, 1990). This corresponds to the density of 6 and 8 plants per row in our experiments. An investigation on the effect of the light environment in pinching cultivation of snapdragons will be required.

In experiment 2, days to flowering of II-1st branches in the non-temporary planting decreased by 30 days compared with the conventional method of raising seedling. Furthermore, the yield of cut flowers from II-2nd branches increased by non-temporary planting. In the conventional method, the delay of growth for rooting may increase the number of days from pinching to flowering in the II-1st branches. Inaba and Ohshiro (2004) reported with 'Maryland Pink' grown by non-temporary planting that the yield of cut flowers from I-branches and II-2nd branches increased, compared with the conventional method. When the results were compared with those of experiment 2 , there was agreement with the yield per plant, but did not with the generation of the branch. In the former study, the planting density was 6 plants per row, and polypropylene (isolation) bed (Super drenbed 85 , Zennoh) was used as a medium. Thus, the difference in the results may be attributed to different cultivation conditions. It is necessary to confirm how branches generate under practical conditions.

In 'Maryland Pink', raised by the conventional method and planted at 6 plants per row, the difference in the number of days from pinching to flowering of the II-1st branch between experiment 1 and 2 was 13 days. In our previous report, there was a difference in time to flowering among years of investigation although the plants were cultivated at the same time (Inaba and Horiuchi, 2003; Inaba and Ohshiro, 2004). This difference could be attributed to differences in meteorological conditions. 
There are two main methods for raising seedlings in the production region. One is temporary planting as a conventional method, like experiment 1 (Inaba, 1994; Hosoya, 1994; Keida, 1994), and the other is direct planting or non-temporary planting, like experiment 2 (Abe and Sasaki, 1994; Inaba, 2001). Non-temporary planting was found to have several advantages, such as shortening of time nursing the seedling, acceleration of II-1st branches flowering and an increase in yield. In particular, flowering of II-1st branches can be accelerated by non-temporary planting, which may enable systematic harvesting.

Cut flower length was not affected by planting density in both experiments 1 and 2. Cut flower length decreased at relatively high night temperatures in pinching cultivation of snapdragons (Inaba and Ohtsuka, 2002; Inaba and Horiuchi, 2003; Inaba and Ohshiro, 2004). However, planting density does not seem to affect the length of cut flowers cultivated under the same temperature condition. The planting density did not affect the node number. Cut flower length and node number of II-1st branches were greater in the conventional method than in non-temporary planting. This is possibly attributed to the delay in the flowering time by about 30 days in the conventional method.

We found that in pinching cultivation, in which flowers were harvested continuously, the yield of I-branches or II-2nd branches decreased after harvesting flowers from II-1st branches with an increase in planting density, which led to the decrease in the yield per plant. However, the yield per square meter at a planting density of 4 plants per row was significantly less than those at 6 and 8 plants per row. For the conventional method (with temporary planting) and non-temporary planting, the planting density at 6 plants per row seems to be suitable. We concluded that the nontemporary planting was a better method because it has several advantages such as increase in the yield of cut flowers, acceleration of flowering in II-1st branches and saving labor to raise seedlings during the summer season.

We are grateful to Dr. Kazuo Ichimura, National Institute of Floricultural Sciences, NARO, Japan, for his valuable advice.

\section{REFERENCES}

Abe, H., Sasaki, T. 1994. Snapdragon. In "Nougyou Gijyutsutaikei Kakihen" (Japanese text) Vol. 8, Noubunkyo, Tokyo, p 81-87.

Corr, B., Laughner, L. 1998. Antirrhinum. In "Ball Redbook 16th ed" Ball Publishing, Illinois, p 356-367.

Flint, H. L. 1960 . Relative effects of light duration and intensity on growth and flowering of winter snapdragon (Antirrhinum majus L.). Proc. Amer. Soc. Hort. Sci. 75: 769-773.

Hedley, C. L. 1974. Response to light intensity and day-length of two contrasting flower varieties of Antirrhinum majus L. J. Hort. Sci. 49: 105-112.

Hosoya, K. 1994. Snapdragon. In "Nougyou Gijyutsutaikei Kakihen” (Japanese text) Vol. 8, Noubunkyo, Tokyo, p 95-100.

Inaba, Z. 1994. Snapdragon. In "Nougyou Gijyutsutaikei Kakihen" (Japanese text) Vol. 8, Noubunkyo, Tokyo, p 55-75.

Inaba, Z. 2001. Snapdragon of Izu. In "Shizuokaken Yasai, Kaki Engeihattatsushi" (Japanese text) Shizuokaken Yasai, Kaki Engeihattatsushi Hensan Iinkai, Shizuoka, p 332-333.

Inaba, Z., Horiuchi, M. 2003. Effects of night temperatures and day length in the winter on the flowering, yields and quality of snapdragon (Antirrhinum majus. L.). (Japanese text with English summary) Hort. Res. (Japan) 2: 199-203.

Inaba, Z., Ohshiro, M. 2003. Effects of starting time of the heating and night temperature setting in winter on the flowering and quality of snapdragons (Antirrhinum majus. L.) (Japanese text with English summary) Hort. Res. (Japan) 2: 303-306.

Inaba, Z., Ohshiro, M. 2004. Effects of the nursing seedling method and winter night temperature on flowering, yields and quality of snapdragons (Antirrhinum majus. L.) (Japanese text with English summary) 


\section{Z. INABA AND M. OHSHIRO}

Hort. Res. (Japan) 3: 273-276.

Inaba, Z., Ohtsuka, H. 2002. Effects of winter night temperature on the flowering of snapdragons (Antirrhinum majus. L.). (Japanese text with English summary) Hort. Res. (Japan) 1: 263-267.

Inaba, Z., Wakasawa, H., Ohtsuka, H. 1997. The effect of pinch treatment on the flowering response in snapdragons (Antirrhinum majus. L.). (Japanese text with English summary) Bull. Shizuoka Agr. Exp. Stn. 42: 51-65.

Keida, S. 1994. Snapdragon. In "Nougyou Gijyutsutaikei Kakihen" (Japanese text) Vol. 8, Noubunkyo, Tokyo, p 101-105.

Maginnes, E. A., Langhans, R. W. 1961. The effect of photoperiod and temperature on initiation and flowering of snapdragon (Antirrhinum majus-variety Jackpot). Proc. Amer. Soc. Hort. Sci. 77: 600-607.

Rogers, M. N. 1992. Snapdragons. In "Introduction to Floriculture. 2nd ed." (ed. by Larson, R.A.) Academic Press, San Diego, p 94-112.

Sanderson, K. C., Link, C. B. 1967. The influence of temperature and photoperiod on the growth and quality of a winter and summer cultivar of snapdragon. Proc. Amer. Soc. Hort. Sci. 91: 598-611.

Tanaka, M. 1990. Photosynthesis and light management. In "Carnation Joukan" (ed. by Yonemura, K.) (Japanese text) Seibundo Shinkosha, Tokyo, p 108-139.

Yonemura, K. 1990. Planting. In "Carnation Gekan" (ed. by Yonemura, K.) (Japanese text) Seibundo Shinkosha, Tokyo, p 83-102. 